\title{
Sistem Simulasi Evakuasi Kebakaran Berbasis Multi Agen
}

\author{
Freska Rolansa*1, Azhari $\mathrm{SN}^{2}$ \\ ${ }^{1}$ Politeknik Negeri Pontianak \\ ${ }^{2}$ Jurusan Ilmu Komputer dan Elektronika, FMIPA UGM, Yogyakarta \\ e-mail: *1 ${ }^{1}$ reska.ilkom@gmail.com ${ }^{2}$ arisn@mail.ugm.ac.id
}

\begin{abstract}
Abstrak
Gedung merupakan salah satu tempat dilaksanakannya berbagai aktivitas dari sejumlah manusia pada waktu tertentu. Pada saat kebakaran gedung terjadi, semua orang yang berada didalam gedung harus melakukan proses evakuasi agar terhindar dari bahaya api. Permodelan dengan agen merupakan salah satu cara menggambarkan kondisi kebakaran di kehidupan nyata, untuk mengurangi biaya dan bahaya yang ditimbulkan pada saat terjadi kebakaran digedung.

Permodelan ini menggunakan pendekatan Multi agen, yang terdiri dari agen karyawan, agen api dan agen pintu exit yang saling berinteraksi dan berkomunikasi. Setiap karakteristik dan perilaku dari agen disimulasikan dengan menggunakan NetLogo pada saat terjadi kebakaran digedung dengan menggunakan skenario perluasan api, skenario penyelamatan, dan proses evaluasi fasilitas pendukung evakuasi.

Pengujian dilakukan terhadap kondisi existing gedung dan perubahan rancangan fasilitas pendukung evakuasi seperti scenario penempatan pintu dan scenario penambahan lebar pintu. Setiap satu pengujian skenario dilakukan sebanyak 5 kali percobaan dengan parameter yang sama dan hasilnya akan dicari nilai rata-rata jumlah manusia yang selamat dan jumlah korban yang terkena api sebagai hasil evaluasi fasilitas pendukung evakuasi, selain itu juga dilakukan pengujian terhadap skenario perluasan api dan skenario penyelamatan untuk melihat karakteristik dan perilaku yang dimiliki agen api dan agen karyawan dalam memberikan aksi terhadap proses evakuasi.
\end{abstract}

Kata kunci : Evakuasi, kebakaran, agen, NetLogo, skenario, evaluasi.

The building is one of place that people do various activities at a certain time. At the time of building fire occurs, all of the people must make the evacuation process in order to avoid the danger of fire. Modeling with Agent is one way to describe the condition of fire in real life, to reduce costs and the danger posed in the event of a fire halls.

This model uses Multi-agent approach, which consists of the employeeagent, fire agent and exit dooragent which interact and communicate. Each of the characteristics and behavior of the agent is simulated using the NetLogo in the event of fire halls using the expansion fire scenario, rescue scenario, and evacuation support facilities to evaluation process.

Tests carried out on the existing condition of the building and changes the support facilities such as the placement of doors and the addition of the door width scenario. Each of the test scenario performed 5 times with the same parameters and the results will be sought value average number of human survivors and the number of victims affected by the fires as a result of the evaluation of evacuation support facility, while also testing the expansion fire and rescue scenario for look at the characteristics and behavior of fire agent and employee agent in evacuation process.

Keywords: Evacuation, Fire, Agent, NetLogo, scenario, evaluation. 


\section{PENDAHULUAN}

$P$ erkembangan jumlah manusia saat ini begitu besar, seiring dengan perkembangannya banyak bangunan besar seperti tempat perbelanjaan, gedung pertemuan, bioskop dan gedung berukuran besar lainya dibangun di Indonesia. Begitu halnya dengan peluang kecelakaan yang terjadi di gedung tersebut salah satunya adalah kebakaran. Pada saat kebakaran terjadi terdapat begitu banyak manusia yang harus keluar dari gedung tersebut untuk menyelamatkan diri mereka. Jumlah mereka yang begitu banyak seperti kerumunan manusia (crowd) berprilaku secara simultan berlari menuju pintu keluar berdesakan, saling mendorong untuk menyelamatkan diri mereka masing-masing, orang dekat atau keluarga mereka sendiri. Mereka harus mampu keluar dari gedung secepat mungkin, dengan menghindari rintangan yang terjadi, dan harus memilih pintu keluar yang tepat agar tidak terluka dan menjadi korban dari kecelakaan tersebut[1].

Evakuasi secara sederhana dapat didefinisikan sebagai pergerakan orang atau masyarakat dari suatu wilayah atau situasi yang terancam oleh terjadinya peristiwa bencana kewilayah yang lebih aman[2]. Tujuan utama evakuasi adalah menyelamatkan nyawa masyarakat. Ketika hal ini tidak dapat dilakukan dengan baik maka evakuasi dapat menyebabkan lebih banyak kematian. Oleh karenanya,selama evakuasi, kemampuan untuk menggerakkan masyarakat dalam jumlah besar dengan waktu yang sangat terbatas sangatlah penting salah satu cara untuk membekali masyarakat dengan pengetahuan tentang rute evakuasi dan tempat yang aman adalah dengan melaksanakan latihan atau drill evakuasi secara regular. Namun demikian, drill kebakaran dalam skala besar sangat mahal dan sulit mengajak massa dalam jumlah besar untuk ikut berpartisipasi.

Proses yang sulit dalam melakukan prediksi performances terhadap proses evakuasi bangunan publik yang berukuran besar dan tampilan yang kompleks serta pendeskripsian situasi menjadi lebih sulit ketika mempertimbangkan interaksi antar manusia yang terlibat pada saat kebakaran terjadi[3].Untuk mengatasi tantangan praktikal, finansial serta kesulitan dalam melakukan ekspose proses evakuasi secara langsung di dunia nyata maka salah satu solusi yang dapat ditempuh adalah dengan membangun dan mengembangkan permodelan evakuasi kebakaran. Meskipun tidak sepenuhnya dapat meniru situasi nyata, permodelan secara praktis dapat meminimalkan berbagai konsekuensi negatif akibat pelaksanaan drill sekaligus memberikan masukan dan wawasan untuk penguatan strategi penyelamatan [2] dan permodelan simulasi dapat melakukan test keilmiahan teori dan hipotesis, melakukan tes strategis dalam mendesain dan melakukan pembuatan ulang phenomena berkaitan dengan teori [4].

Salah satu pemanfaatan simulasi adalah proses evakuasi tsunami, Munadi dkk.(2012) menjelaskan aplikasi simulasi evakuasi tsunami (SET) berbasis multi agen untuk wilayah Calang, di Kabupaten Aceh Jaya, Provinsi Aceh. Berdasarkan hasil simulasi, dapat ditegaskan bahwa rencana evakuasi yang di implementasikan saat terjadi bencana sangat berperan dalam mengurangi jumlah korban selama proses evakuasi selain itu Bode dkk.(2013) melakukan pengamatan terhadap perilaku kolektif dari kerumunan manusia terjadi karena adanya interaksi lokal antar setiap individu, kemudian melakukan pengembangan lingkungan virtual yang interaktif dalam mempelajari pengambilan keputusan rute pintu keluar di dalam simulasi evakuasi selain itu Shi dkk.(2009) mengembangkan model yang dinamakan AIEva, dengan pendekatan model matematika evakuasi secara dinamis berbasis agen yang bertujuan dalam memberikan simulasi evakuasi pekerja di dalam lingkungan gedung publik yang terbakar yang akan berguna dalam mengidentifikasi keamanan terhadap kebakaran untuk perencanaan secara arsitektural. Berdasarkan penelitian-penelitian yang telah ada, belum ada penelitian yang dimplementasikan pada gedung tertutup menggunakan multi agen yakni agen manusia, agen api dan agen pintu yang dapat berkoordinasi dan berkomunikasi oleh karena itu dibuatlah simulasi evakuasi kebakaran berbasis Multi agen pada saat proses simulasi evakuasi terjadi didalam gedung, dalam upaya meningkatkan performance proses evakuasi digedung serta meminimalkan jumlah korban dan memaksimalkan jumlah manusia yang selamat. Selain itu, simulasi ini juga mempresentasikan karakter fisik lingkungan simulasi evakuasi kebakaran yang terjadi digedung.

IJCCS Vol. 9, No. 1, January 2015 : $101-110$ 


\section{METODE PENELITIAN}

Proses diawali dengan merepresentasi layout gedung direktorat, kemudian dilakukan inisialisasi dengan parameter jumlah orang, posisi orang pada setiap lantai, posisi pintu, lebar pintu, titik api, jumlah titik api, kecepatan angin dan arah angin. Setelah tahapan inisialisasi dilanjutkan apakah titik api akan meluas jika titik api meluas maka terjadilah proses pembakaran yang terbagi menjadi 2 bagian. Bagian pertama adalah pada saat proses pembakaran terjadi dilakukan pengecekan apakah posisi api sama dengan posisi pintu exit jika sama maka api akan melakukan pembakaran terhadap berbagai bahan disekitarnya dan membakar pintu. Bagian kedua adalah pada saat api meluas, orang yang berada di dalam gedung harus segera keluar, dengan melakukan proses pergerakan, seiring pergerakan nya akan dilakukan pengkondisian kembali apakah posisi orang sama dengan posisi api, jika posisi nya sama maka orang tersebut menjadi korban dari api, dan jika berbeda maka orang tersebut akan terus bergerak menuju pintu exit. Pergerakan orang akan berhenti dan orang tersebut dinyatakan sebagai manusia selamat ketika posisi pintu exit sama dengan posisi orang tersebut, akan tetapi jika orang tersebut belum mencapai posisi pintu exit maka prosesnya akan berulang di kondisi apakah posisi api dan orang tersebut berada pada posisi yang sama. Setelah orang tersebut dinyatakan selamat akan diberikan pilihan apakah akan melakukan perubahan terhadap fasilitas pendukung evakuasi yang menerapkan analisis teori dalam melakukan design ulang fasilitas pendukung evakuasi gedung, kemudian tahapan berikutnya adalah kembali pada tahap inisialisasi awal. Setelah melewati proses yang sama maka akan dianalisa hasilnya untuk digunakan sebagai bahan evaluasi dalam melakukan design fasilitas pendukung evakuasi gedung seperti diperlihatkan pada Gambar 1

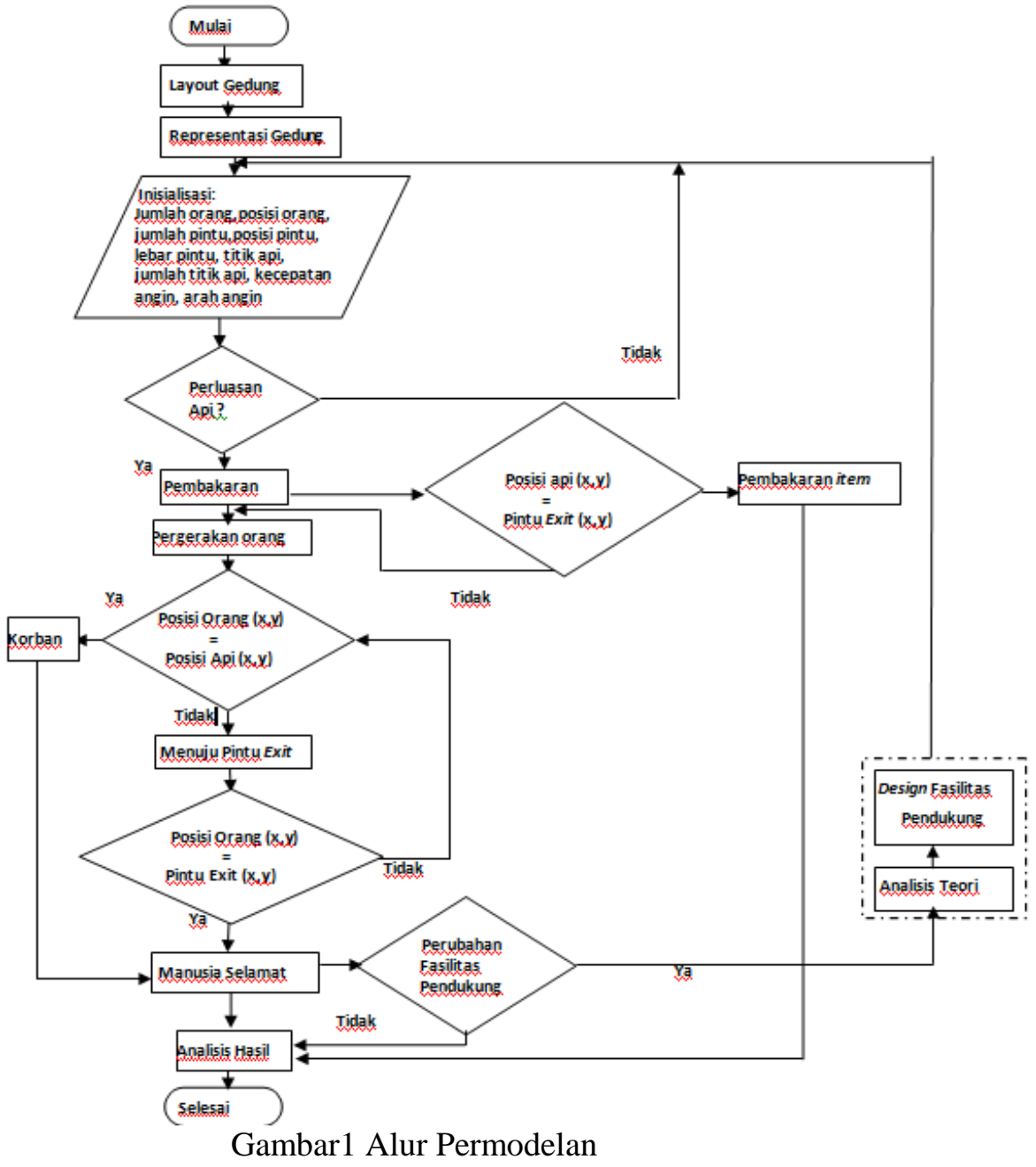


Hasil penelitian yang diperoleh dapat diuraikan berdasarkan pencapaian tujuan utama permodelan evakuasi kebakaran yaitu memaksimalkan jumlah manusia yang selamat dan meminimalkan jumlah korban. Dalam penelitian ini data yang digunakan adalah data generik,berupa data gedung direktorat politeknik yang terdiri dua lantai, yang setiap lantai memiliki luas $672 \mathrm{~m} 2$, dengan panjang 28 meter dan lebar 24 meter dan memiliki banyak ruangan dan setiap ruangan memiliki ukuran yang bervariasi dan berbeda, serta dilengkapi dengan sebuah tangga serta dua buah pintu yang digunakan untuk keluar pada saat evakuasi, skenario ini dikonfigurasi di NetLogo dengan persegi panjang yang berukuran $280 \times 240$ patches, yang setiap 1 patches nya dengan panjang dan lebar 0.1 meter yang berarti 1 patches adalah 1 area yang berukuran $0.1 \mathrm{~m}^{2}$, kemudian data manusia direpresentasikan dengan simbol person untuk skenario ini berukuran $0.4 \mathrm{~m}^{2}$. Tahapan penelitian menggunakan metode prometheus, pada diagram overview inimerumuskan dan merancang mekanisme kerja agen secara menyeluruh[5] sepertidisajikan pada Gambar 2.

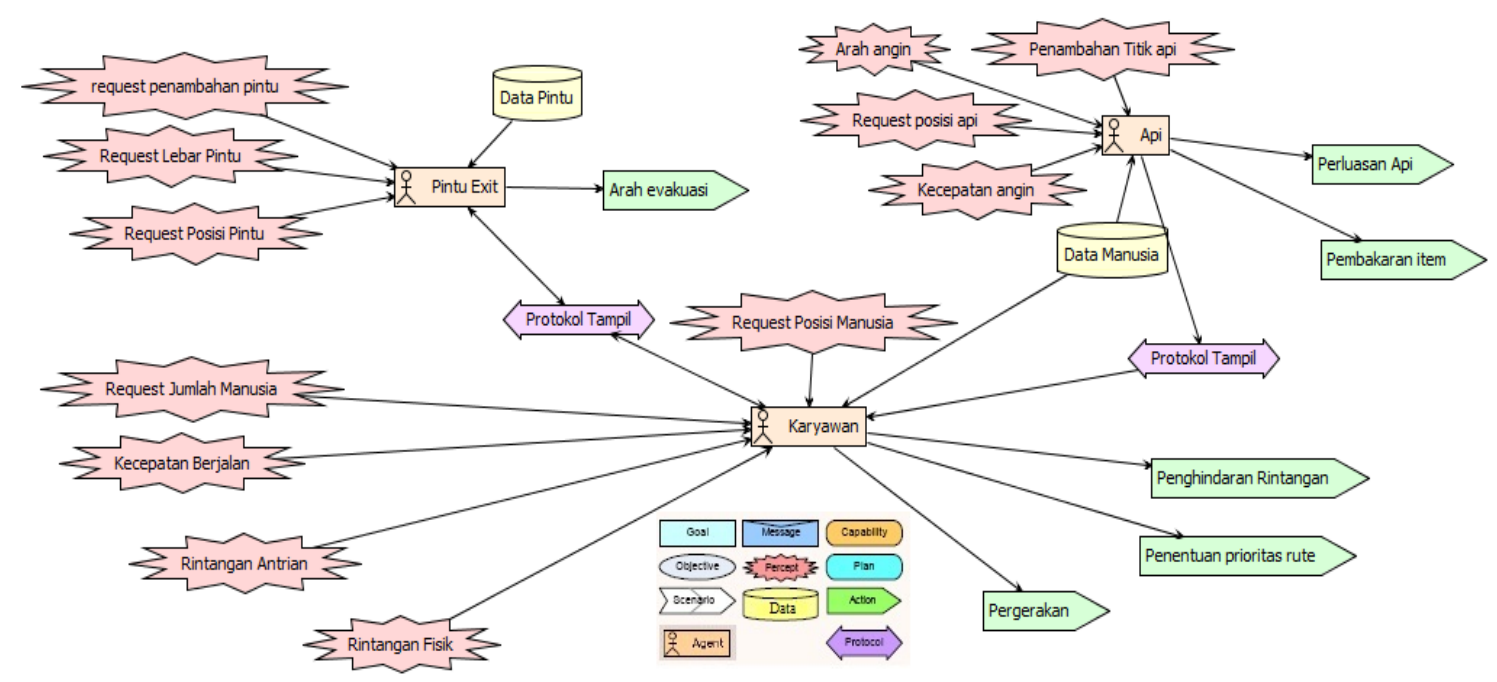

Gambar 2 Diagram Overview

Pada Gambar 2 dapat dilihat bahwa terdapat 3 agen yang berperan yakni Agen Karyawan, Agen Api dan Agen Pintu Exit. Agen Karyawan merupakan agen utama yang berinteraksi pada model ini, AgenKaryawan terdiri dari atribut-atribut sebagai berikut: Posisi awal, Posisi, Kecepatan, Jarak pandang, dan Ukuran_tubuh. Posisi awal mendeskripsikan Letak awal AgenKaryawan manusia pada saat berada dilingkungan sistem, posisi manusia diatur secara random di lantai 1 ataupun di lantai 2, Posisi mendeskripsikan perubahan letak agen karyawan pada waktu tertentu dilingkungan sistem, Kecepatan mendeskripsikan Kecepatan manusia dalam proses evakuasi dalam satuan meter/second $(\mathrm{m} / \mathrm{s})$, pada sistem ini kecepatan manusia diatur secara random dengan variasi kecepatan dimulai dari $0,1 \mathrm{~m} / \mathrm{s}$ sampai pada kecepatan maksimum 1,2 m/s. Jarak Pandang mendeskripsikan daerah/range yang masih tampak pada lokasi tertentu sesuai dengan posisi AgenKaryawan, jarak pandang yang digunakan sejauh 10 meter tanpa melewati penghalang berupa dinding ruangan pada sistem, dan Ukuran_tubuh mendeskripsikanbesarnya luasan tubuh manusia terhadap lingkungan sistem, pada sistem ini luasan tubuh manusia diatur dengan luasan terkecil 0,1 meter sampai pada luasan maksimum 0,4 meter.Agen Karyawan kemampuannya adalah bergerak dalam melakukan aksinya untuk pergerakan keluar gedung, penghindaran rintangan dan penentuan prioritas rute, berikut ini salah satu pergerakanagenkaryawan pada saat evakuasi, agen karyawan harus bergerak dengan cara terlebih dahulu menentukan rute yang dipilih berdasarkan prioritas dan posisi agen karyawan berada, jika berada dilantai 1 maka pintu exit menempati prioritas pertama, kemudian pintu ruangan, dan arah evakuasi berdasarkan jarak pandang yang dimiliki agent karyawan. Penentuan rute dapat dilihat pada Gambar 3. 


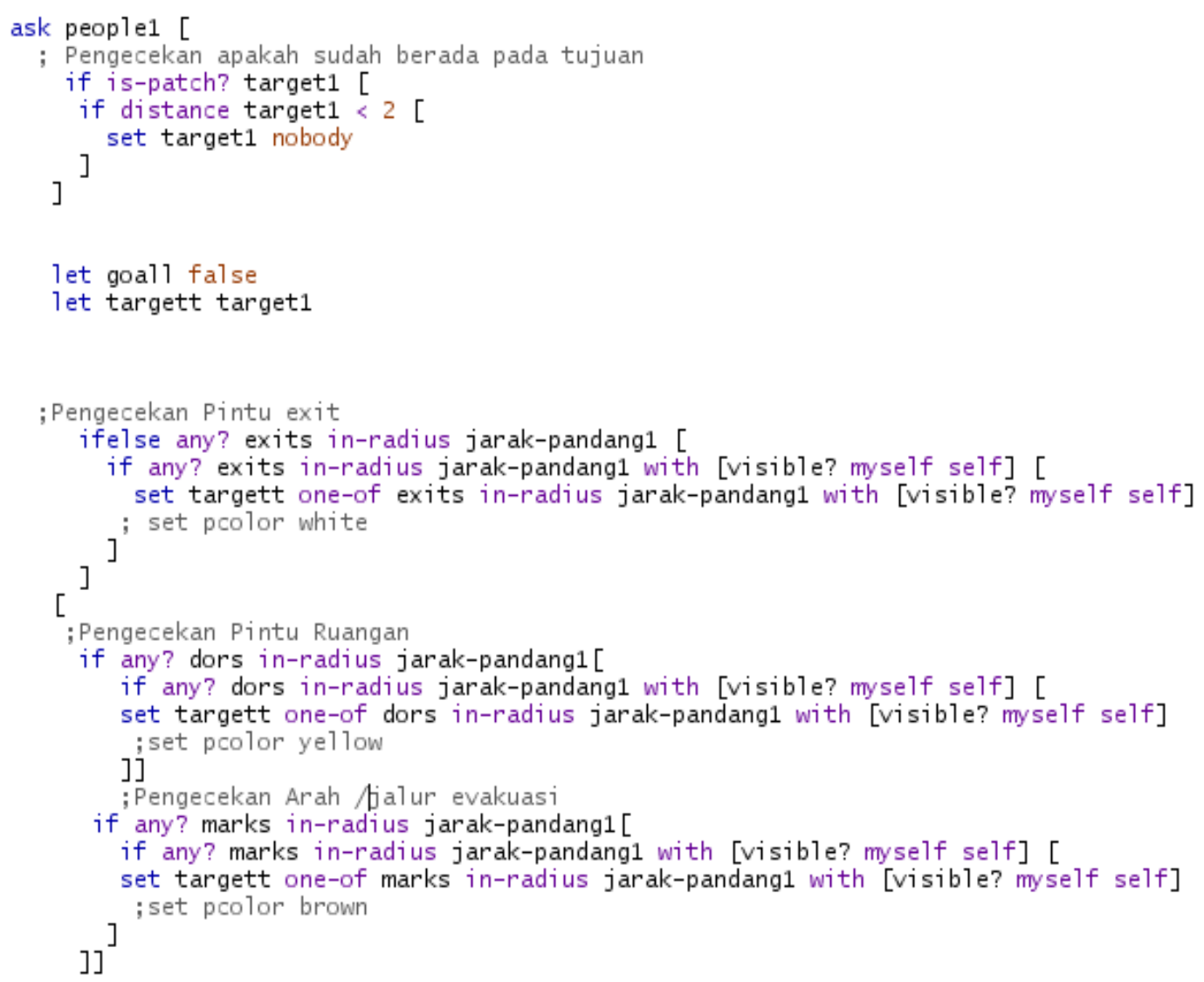

\section{Gambar 3 Penentuan Rute}

Agen Api memiliki peran dalam menentukan korban. Korban adalah manusia yang berada didalam gedung/lingkungan sistem disaat posisi manusia sama dengan posisi api ketika mengalami perluasan. Agen Api terdiri dari atribut-atribut sebagai berikut: Ukuran awal, range, Jumlah,Posisi, dan Durasi. Ukuran awal mendeskripsikanukuran dari awal titik api, ukuran awal dari titik api adalah 0,1 meter, Range mendeskripsikan jarak api terhadap posisi awal api ketika meluas pada lingkungan sistem. Range api dipengaruhi oleh arah angin dan kecepatan angin, semakin cepat angin maka perbesaran api akan semakin membesar sesuai dengan arah angin. Pengaturan arah angin ditentukan berdasarkan sudut derajat lingkaran, jika 90' artinya angin mengarah ke barat, dan 180' angin mengarah ke selatan dan seterusnya, sedangkan kecepatan angin diatur dengan kecepatan $0,1 \mathrm{~m} / \mathrm{s}$ sampai pada kecepatan $0.5 \mathrm{~m} / \mathrm{s}$. Jumlah mendeskripsikan jumlah titik api, pada sistem ini dirancang penambahan titik api secara interaktif dengan menambahkan titik api berdasarkan posisi yang diinginkan pengguna. Posisi mendeskripsikan posisi luasan api terhadap sistem, Durasi mendeskripsikan lama/waktu yang dibutuhkan api saat membesar/memperluas.Agen Api memiliki kemampuan untuk melakukan pembakaran terhadap fasilitas pendukung evakuasi (pintu exit, tangga, koridor, ramp), dinding dan manusia yang berada di dalam gedung dengan aksi perluasan api dan pembakaran item sedangkan Agen Pintu Exit memiliki peran dalam menentukan manusia yang selamat. Manusia selamat adalah manusia yang bergerak keluar dari gedung melewati Pintu Exit. Agen Pintu Exit memiliki atribut Posisi, dan Ukuran. Posisi mendeskripsikan letak Pintu Exit pada sistem, dan Ukuran mendeskripsikan Lebar dari Pintu Exit dalam satuan meter.Agen ini memiliki kemampuan memberikan arah untuk keluar dalam aksi memberikan arah menuju pintu exit. 


\section{HASIL DAN PEMBAHASAN}

Pengujian dilakukan terhadap 3 skenario utama yakni skenario perluasan api, skenario penyelamatan dan Skenario evaluasi.Pengujian pada skenario perluasan api dimulai dari adanya satu titik api atau lebih pada posisi tertentu, berdasarkan pengujian yang dilakukan dengan posisi awal salah satu titik api di ruang staff TU yang berada di lantai 2. Setelah itu api akan mengalami perluasan kesegala arah dan membakar berbagai item dan fasilitas yang ada digedung seperti ditunjukan pada Gambar 4.

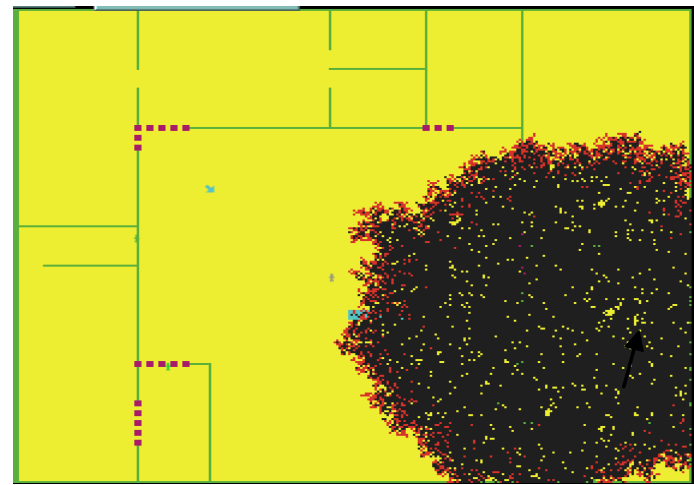

Gambar 4 Perluasan api diruang tata usaha

Berdasarkan Gambar 4 menunjukan api telah memperluas dan membakar ruang tata usaha, dinding dan pintu ruang tata usaha beserta tangga pada koridor di lantai 2 .

Selain itu dilakukan pengujian pengaruh arah angin dan kecepatan angin pada perluasan api, dan salah satu hasil yang dilakukan ketika kecepatan angin ditambah maka perbesaran api akan semakin cepat, serta ketika arah angin ditentukan menuju sudut 180' / menuju ke selatan maka perluasan api menuju arah yang sama yakni keselatan seperti ditunjukan pada Gambar 5.

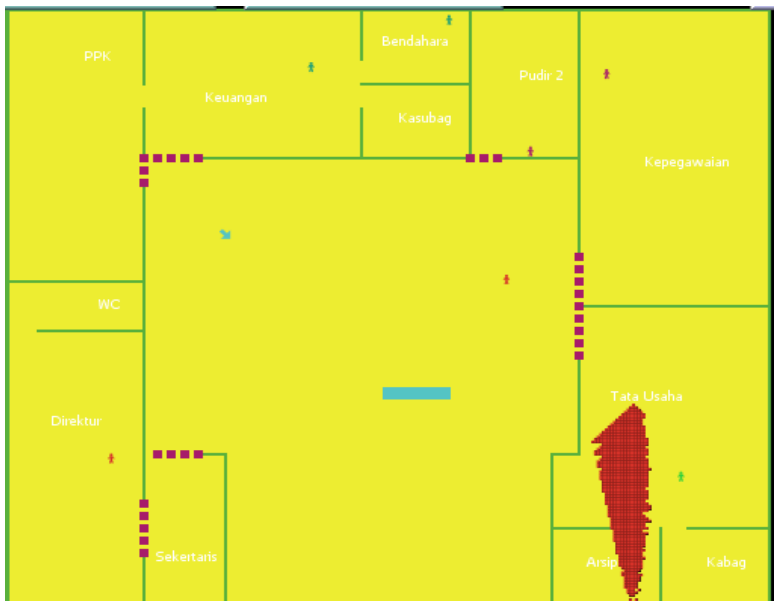

Gambar 5 Arah angin menuju selatan

Pengujian pada skenario penyelamatan ditentukan kedalam dua bagian yakni penentuan rute dan pergerakan. Penentuan rute agent karyawan harus memilih rute berdasarkan prioritasnya, rute yang memiliki prioritas pertama adalah rute menuju pintu exit dilantai 1 atau rute menuju tangga dilantai 2 , kemudian rute menuju pintu ruangan dan yang terakhir rute menuju arah evakuasi dengan simbol arah panah. Pergerakan agenkaryawan berdasarkan dari penentuan rute yang telah dipilih oleh agen manusia. Pergerakan agen karyawan untuk menuju pintu exit dengan jalur berwarna putih, jalur yang telah ditempuh menuju pintu ruangan berwarna kuning, dan jalur menuju arah evakuasi berwarna coklat seperti diperlihatkan pada Gambar 6. 


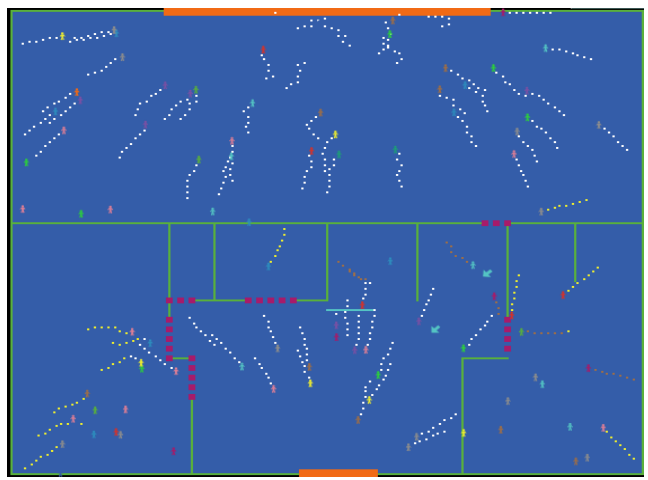

Gambar 6 Pergerakan berdasarkan rute

Dari hasil pengujian yang telah dilakukan agen karyawan dapat menghindari rintangan yang berupa dinding dan agen karyawan lain. Agen karyawan dapat bergerak maju, berbalik arah, kekiri, dan kekanan berdasarkan posisinya serta agen karyawan juga dapat menunggu agen karyawan lain pada saat terjadi kerumunan pada posisi tertentu yang akan bergerak agar terhindar dari tabrakan. Salah satu contoh cara yang digunakan agen karyawan untuk menghindari dinding dengan berbalik arah, kemudian menetapkan pintu ruangan sebagai penentuan rute yang dipilih dan bergerak menuju pintu ruangan kemudian setelah mencapai pintu ruangan, agen karyawan menetapkan rute berikutnya yakni pintu exit, dan agen karyawan tersebut bergerak menuju pintu exit seperti dilihat pada Gambar 7.

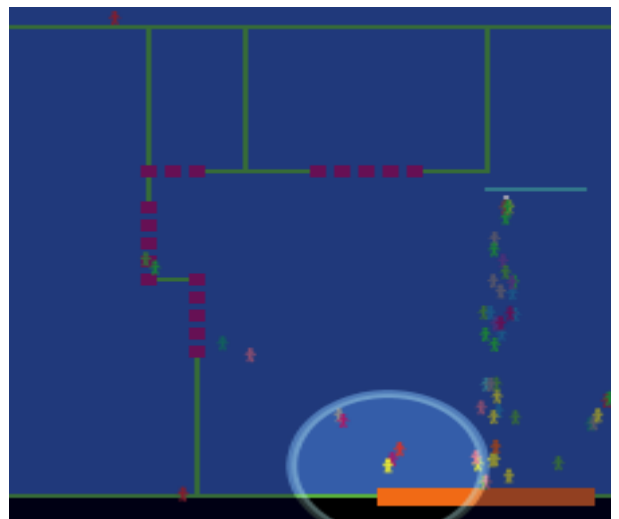

Gambar 7 Pergerakan agent karyawan menuju pintu exit

Pengujian berikutnya adalah skenario evaluasi fasilitas pendukung berdasarkan jumlah manusia yang selamat dan korban setelah itudilakukan skenario yang berbeda dalam memperlebar pintu utama yang digunakan sebagai pintu exit dan menempatkan pintu exit pada posisi tertentu dalam proses evaluasi. Skenario ini dilakukan untuk membandingkan kondisi existing gedung dengan rancangan fasilitas pendukung yang akan diajukan.

Pengujian proses evaluasi fasilitas pendukung evakuasi gedung ini menghasilkan variasi jumlah manusia yang selamat dan menjadi korban kebakaran digedung, berdasarkan 5 percobaan fasilitas pendukung evakuasi gedung terhadap kondisi existing gedung dengan menggunakan waktu evakuasi maksimum $=486$ detik. Berdasarkan kondisi existing gedung maka diperoleh jumlah rata-rata manusia yang selamat adalah 196 orang dan jumlah korban dengan rata-rata 4 orang dari keseluruhan jumlah manusia sebanyak 200 orang yang berada didalam gedung setelah dilakukan 5 percobaan dengan parameter yang sama terhadap kondisi existing yakni dengan menggunakan waktu evakuasi maksimum $=486$ detik, jumlah manusia yang selamat dan korban dengan parameter jumlah manusia di lantai $1=100$ orang, jumlah manusia di lantai $2=100$ orang, lebar pintu utama $=2$ meter, lebar pintu alternatif $=14$ meter 
dan posisi api berada di lantai 2 diruang Tata usaha, telah dilakukan 5 kali percobaan yang setiap percobaan posisi manusia dilantai 1 dan dilantai 2 diatur secara random diperoleh hasilseperti ditunjukan pada Gambar 8.

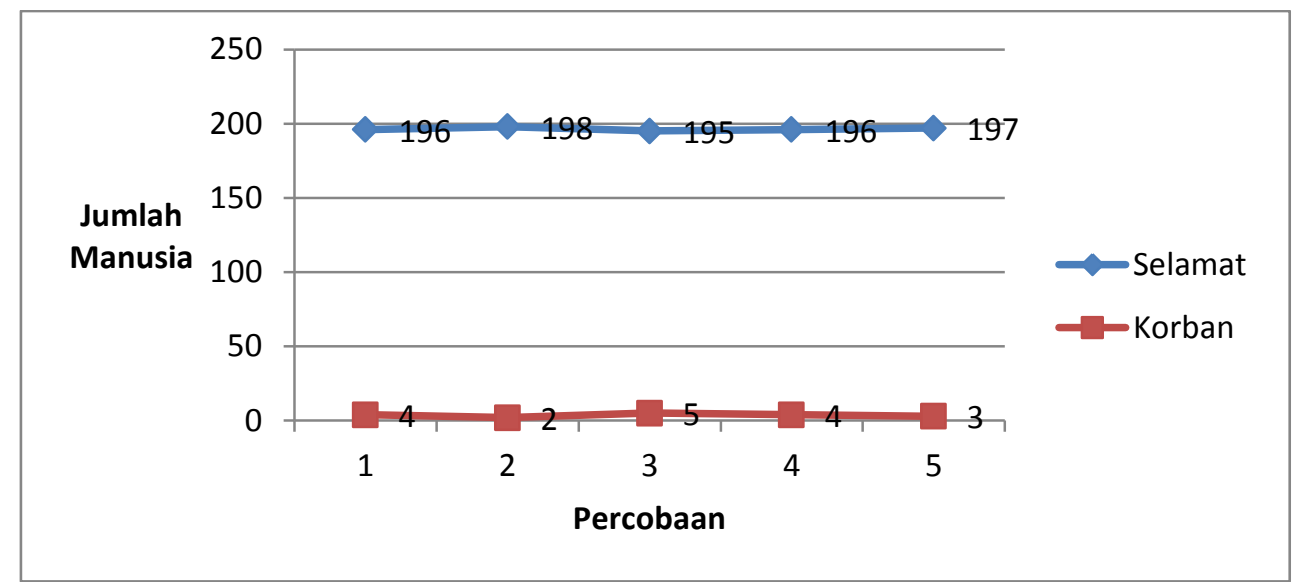

Gambar 8 Jumlah Manusia Selamat dan Jumlah Korban

Untuk melihat lebih jauh keterkaitan fasilitas pendukung evakuasi gedung, dilakukan dengan menempatkan pintu exitdanmenambah lebar dari pintu exit.Skenario penempatan pintu exit dilakukan dengan menempatkan pintu exit dengan ukuran 4 meter diposisi yang berbeda dengan sebelumnya (existing) seperti ditunjukan pada Gambar 9.

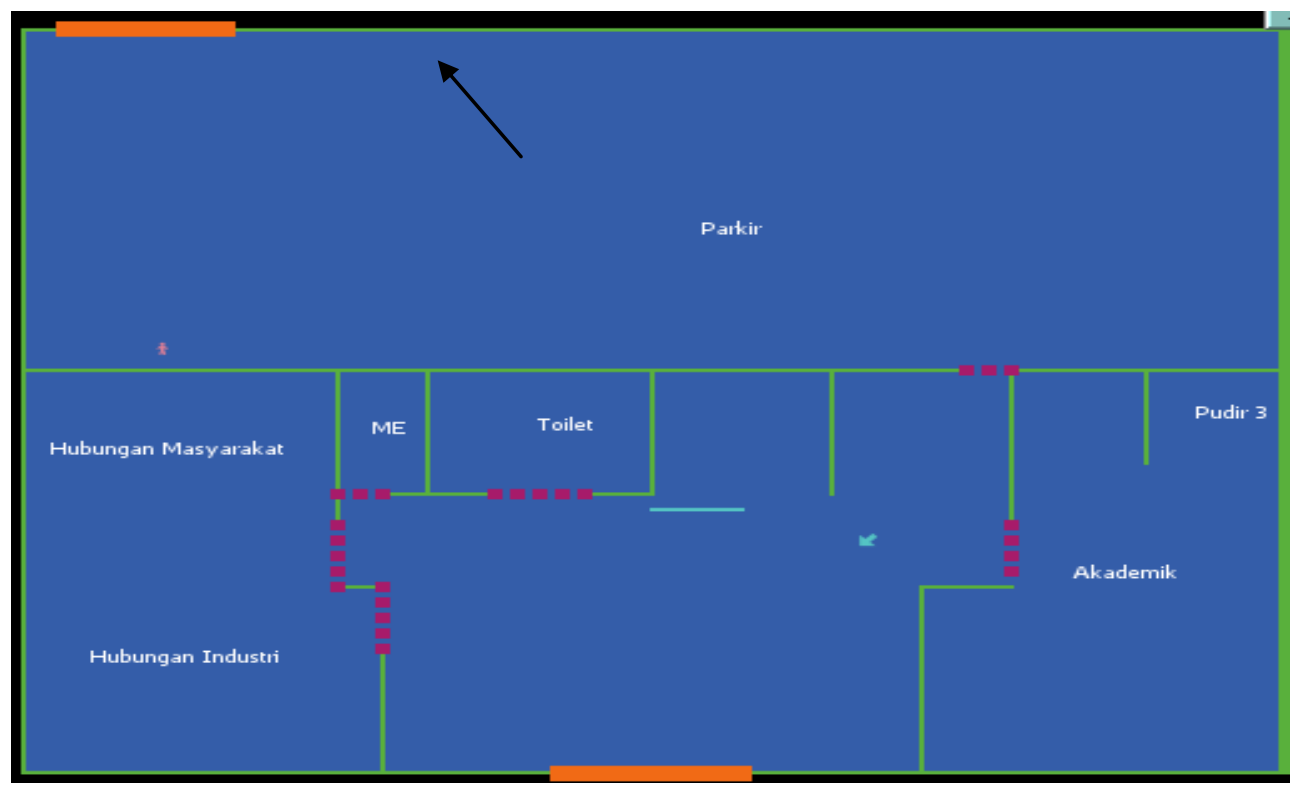

Gambar 9 Penempatan Pintu exit

Setelah dilakukan 5 kali percobaan dengan parameter jumlah manusia di lantai $1=100$ orang, jumlah manusia di lantai $2=100$ orang, lebar pintu utama $=4$ meter, lebar pintu alternatif $=4$ meter dengan posisi pintu yang berbeda dari sebelumnya atau berbeda dari kondisi existing gedung dan posisi api berada dilokasi yang sama yakni di lantai 2 diruang Tata usaha, serta dengan posisi manusia dilantai 1 dan dilantai 2 yang diatur secara random diperoleh hasiljumlah manusia yang selamat meningkat menjadi rata-rata 197 orang dan jumlah korban 
menurun menjadi rata-rata 3 orang disebabkan perubahan letak dari pintu exit dan lebar dari pintu exit.

Setelah itu dilakukan skenario berikutnya dengan memperlebar ukuran pintu utama yang digunakan sebagai pintu exit yang semula pintu utama lebarnya 2 meter menjadi 4 meter dengan posisi pintu exit yang sama. Parameter lain dilakukan pengaturan dengan nilai yang sama dengan kondisi existing gedung yakni jumlah manusia dilantai $1=100$ orang, jumlah manusia di lantai $2=100$ orang, lebar pintu alternatif $=14$ meter, posisi api berada dilokasi yang sama yakni di lantai 2 diruang Tata usaha, dengan posisi manusia dilantai 1 dan dilantai 2 yang diatur secara random dengan waktu evakuasi maksimum yang sama. Hasil dari 5 percobaan rata-rata jumlah manusia yang selamat menjadi 198 lebih besar atau meningkat dari kondisi existing gedung dan skenario penempatan pintu exit. Selain itu juga dapat dilihat ratarata jumlah korban hanya 2 orang, yang menunjukan penurunan bila dibandingkan skenario sebelumnya terhadap jumlah rata-rata korban.

\section{KESIMPULAN}

Berdasarkan hasil dan evaluasi kemampuan agen, beberapa kesimpulan dapat diperoleh sebagai berikut :

1. Setiap agenmemiliki karakteristik dan perilaku yang berbeda,agenkaryawan dengan karakteristik yang dimilikinya dapat menentukan rute dan bergerak sesuai dengan rute yang dipilih, dan dapat bergerak apabila terjadi kerumunan dengan menunggu agen karyawan lain bergerak, selain itu juga agen karyawan dapat menghindari rintangan berupa dinding dan agen karyawan lain yang berada pada posisi menghalangi jalan, agenapi dengan karakteristik yang dimilikinya dapat memperbesar dan memperluas diri kesegala arah atau ditentukan berdasarkan kecepatan dan arah angin, sedangkan agen pintu exitdengan karakternya mampu memberikan arah rute evakuasi dan berperan dalam proses keluarnya manusia dari dalam gedung.

2. Permodelan ini melibatkan tiga agen yang saling berhubungan/ berkomunikasi yakni agen karyawan, agen pintu exit, dan agenapi sehingga pada penelitian ini sudah menerapkan sistem multi agen.

3. Simulasi evakuasi kebakaran mampu melakukan evaluasi terhadap designdan perubahan terhadap salah satu fasilitas pendukung evakuasi yakni pintu exit dengan penempatan pintu yang berbeda dengan kondisi existing gedung dan penambahan lebar pintu berdasarkan hasil jumlah manusia yang selamat dan jumlah korban.

\section{SARAN}

Saran pada penelitian ini adalah Pengembangan permodelan evakuasi kebakaran ini dapat dikembangkan secara lebih dinamis terutama dalam melakukan design gedung secara interaktif dan dapat dikustomisasi dengan mudah, selain itu juga permodelan ini dapat dikembangkan dengan algoritma dan metode lainnya misalnya dalam penentuan rute terpendek menggunakan algoritma particle swarm optimization (PSO).

\section{UCAPAN TERIMA KASIH}

Penulis mengucapkan terima kasih kepada Orang tua, dan istri yang telah memberi dukungan Doa terhadap penelitian ini. 


\section{DAFTAR PUSTAKA}

[1] Almeida, J.E., Kokkinogenis, Z., Rosseti, R.J.F., 2010, NetLogo Implementation of anEvacuation Scenario, Artificial Intelligence and Computer Science Laboratory (LIACC), Department of Informatics Engineering (DEI), SFRH/BD/72946/2010 and SFRH/BD/67202/2009.

[2] Munadi, K., Nasaruddin, Nurdin,Y. , dan Dirhamsyah, M., 2012, Simulasi evakuasi Tsunami berbasis Multi Agent sebagai media edukasi kebencanaan. Prosiding Insinas 2012, Universitas Syiah Kuala, 29-30 November 2012.

[3] Shi, J., Ren, A., Chen, C., 2009, Agent-based evacuation model of large public buildings under fire conditions,Science Direct Journal, Automation in Construction, Vol. 18, 338347.

[4] Pan, S., Han, C.S., Dauber, K., and Law, K.H., 2007, A multi-Agent based framework for the simulation of human and social behaviors during emergency evacuations, the Center for Integrated Facility Engineering, Stanford University.

[5] Munadi, K., Nasaruddin, Nurdin,Y., dan Dirhamsyah, M., 2012, Simulasi evakuasi Tsunami berbasis Multi Agent sebagai media edukasi kebencanaan. Prosiding Insinas 2012.

[6] Shi, J., Ren, A., Chen, C., 2009, Agent-based evacuation model of large public buildings under fire conditions, 2009, Science Direct Journal, Automation in Construction 18 (2009) $338-347$.

[7] Bode, N.W.F.,Codling, E.A.,2013, Human exit route choice in virtual crowd evacuations, ScienceDirect, Animal Behaviour 86 (2013) 347e358.

[8] Azhari, 2010, Pengembangan Model Monitoring Proyek Perusahaan Berbasis Multiagen Cerdas, Disertasi, Program Studi S3 Ilmu Komputer FMIPAUGM, Yogyakarta. 